\title{
Parenteral penicillin for children with meningococcal disease before hospital admission: case-control study
}

Anthony Harnden, Nelly Ninis, Matthew Thompson, Rafael Perera, Michael Levin, David Mant, Richard Mayon-White

\begin{abstract}
Objective To explore the impact on mortality and morbidity of parenteral penicillin given to children before admission to hospital with suspected meningococcal disease.

Design Retrospective comparison of fatal and non-fatal cases. Setting England, Wales, and Northern Ireland; December 1997 to February 1999.

Participants 158 children aged 0-16 years (26 died, 132 survived) in whom a general practitioner had made the diagnosis of meningococcal disease before hospital admission. Results Administration of parenteral penicillin by general practitioners was associated with increased odds ratios for death (7.4, 95\% confidence interval 1.5 to 37.7$)$ and complications in survivors (5.0, 1.7 to 15.0). Children who received penicillin had more severe disease on admission (median Glasgow meningococcal septicaemia prognostic score (GMSPS) $6.5 v 4.0$, $\mathrm{P}=0.002)$. Severity on admission did not differ significantly with time taken to reach hospital.

Conclusions Children who were given parenteral penicillin by a general practitioner had more severe disease on reaching hospital than those who were not given penicillin before admission. The association with poor outcome may be because children who are more severely ill are being given penicillin before admission.
\end{abstract}

\section{Introduction}

General practitioners in the United Kingdom are currently expected to carry benzyl penicillin in their emergency bags and to administer it parenterally before hospital admission whenever they suspect a diagnosis of meningococcal disease. This guidance reflects the potential of the disease to cause death in a matter of hours and the excess morbidity and mortality associated with delays in treatment. Observational studies that have attempted to assess the impact of such use in clinical practice, however, have reported conflicting results. In 1992 Cartwright et al reported a $40 \%$ reduction in case fatality in children given parenteral penicillin before admission. ${ }^{1}$ In contrast, two more recent studies from Denmark report a twofold to threefold increase in mortality associated with antibiotics given before admission. ${ }^{2}$ We report data that allow further exploration of this important issue.

\section{Methods}

From 1997 to 1999 the Royal College of Paediatrics and Child Health (RCPCH) and the paediatric department at Imperial College London conducted a study of 190 fatal cases of menin- gococcal disease in children in England, Wales, and Northern Ireland. For each case, researchers approached three children who survived meningococcal disease as controls matched by age group (four strata) and region. ${ }^{4}$ The parents of 544 children (114 who died, 430 who survived) consented to participate (fig 1). We restricted our analysis to the subset of 158 children (26 who died, 132 who survived) in whom meningococcal disease was diagnosed by general practitioners before admission to hospital and who were therefore eligible to receive penicillin before admission.

We collected and corroborated data from six sources: questionnaires with parents, telephone interviews with general practitioners (conducted by NN), copies of primary care records (including notes made by deputising services), hospital referral letters, and records of complaints made to health authorities. We obtained information about progression of symptoms (from the parent); the severity of the illness and the provisional diagnosis at the general practice consultation at which the referral decision was made (from the medical record or telephone interview with the general practitioner, or both); the severity of the illness at hospital admission (from the hospital case record); and the time delays involved at each stage. When the information from each source differed, we used contemporaneous medical records rather than questionnaires completed after the event.

Severity of illness in general practice was dichotomised and categorised as "severe" if one or more of the following items were

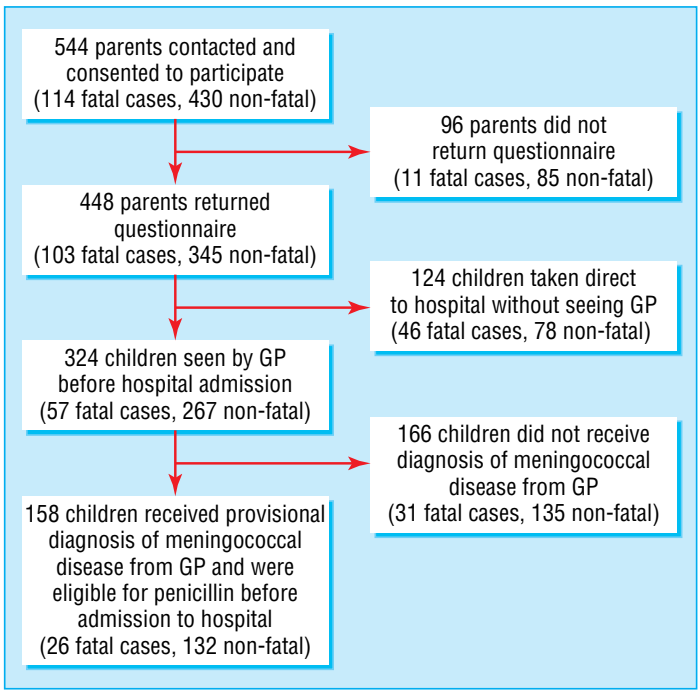

Fig 1 Derivation of the sample of children eligible for penicillin before admission to hospital because of suspected meningococcal disease 
recorded in the medical record: 999 or blue light ambulance call; circulatory collapse (on basis of vital signs or statement such as "shocked," "shut down"); or loss of consciousness. Severity of illness on hospital admission was assessed by calculating the Glasgow meningococcal septicaemia prognostic score (GMSPS) on the basis of data extracted from the hospital admission record; this was available for 116 children. Data on complications (renal, cardiovascular, or respiratory failure; neurological complication; tissue necrosis requiring excision or amputation) among survivors were ascertained from hospital records and parents for 108 children.

We used general practice records or the parental questionnaire, or both, to ascertain whether parenteral penicillin was administered before admission in 152 children. We have expressed the effects of penicillin and the other factors considered as odds ratios rather than risk ratios because of the case-control approach used to identify the cohort. Adjustment of crude odds ratios was done by logistic regression using SPSS version 12. The factors included in the logistic model were sex, pervious use of oral antibiotics, duration of illness, meningococcal serotype, presence of haemorrhagic rash, presentation with septicaemia, and severity assessed by the general practitioner.

\section{Results}

Parenteral penicillin was given to 105 children and not given to 47 children. In six children we could not determine whether penicillin had been given. The most common reason given by the general practitioner for not giving penicillin was uncertainty in the diagnosis $(27 / 47,57 \%)$, mainly because the rash was not haemorrhagic. Other reasons included penicillin allergy (seven) and to avoid any delay in hospital admission (six). We could not ascertain the reason for seven children.

The table shows that penicillin given before admission was associated with a sevenfold increase in risk of death, after adjustment for identified confounding factors (odds ratio 7.4, 95\% confidence interval 1.5 to 37.7). Fifty seven children (see methods) who survived experienced complications. The children who had received penicillin had a higher rate of complications (5.0, 1.7 to 15.0), as did those children with serogroup C (3.3, 1.9 to 10.4 ), and those rated by the general practitioner as having severe disease $(2.9,1.1$ to 7.5$)$.

Figure 2 shows the severity of disease when the children reached hospital according to the time taken to get there and whether or not the child had already received penicillin. Children who had received penicillin had more severe disease (median GMSPS score $6 v 4$, Mann-Whitney $\mathrm{U}$ test $\mathrm{P}=0.002$ ) than those who did not receive penicillin. In both groups severity decreased with the time taken to reach hospital. There was no significant difference, however, in the slope of the regression lines between children who did and did not receive antibiotics (test of equal slopes in linear regression, $\mathrm{P}=0.503$ ).

\section{Discussion}

Our data confirm results from previous retrospective studies from Denmark in showing an association between penicillin treatment in the community and poor outcome. Penicillin is more likely to be given if the child is extremely unwell, and the authors of one of the Danish papers explicitly drew attention to the likelihood of unadjusted confounding by severity. ${ }^{2}$ Though we had more data on severity before admission, the general practitioner's assessment of severity was not strongly predictive of mortality (odds ratio 1.8). This may have been because we had
Odds of death associated with administration of pre-hospital penicillin and other pre-hospital factors in 158 children in whom meningococcal disease was suspected by a general practitioner before admission. Figures are numbers (percentages) of children

\begin{tabular}{|c|c|c|c|c|}
\hline & $\begin{array}{l}\text { Deaths } \\
(\mathrm{n}=26)\end{array}$ & $\begin{array}{c}\text { Survivors } \\
(n=132)\end{array}$ & $\begin{array}{l}\text { Unadjusted odds } \\
\text { ratio }(95 \% \mathrm{CI})\end{array}$ & $\begin{array}{l}\text { Adjusted odds* } \\
\text { ratio }(95 \% \text { Cl) }\end{array}$ \\
\hline Male & $17(65)$ & $69(52)$ & $\begin{array}{c}1.72 \\
(0.67 \text { to } 4.54)\end{array}$ & $\begin{array}{c}1.86 \\
(0.66 \text { to } 5.12)\end{array}$ \\
\hline $\begin{array}{l}\text { Penicillin given before } \\
\text { admissionł }\end{array}$ & $\begin{array}{c}22 / 24 \\
(92)\end{array}$ & $\begin{array}{c}83 / 128 \\
(65)\end{array}$ & $\begin{array}{c}5.96 \\
(1.27 \text { to } 38.50)\end{array}$ & $\begin{array}{c}7.45 \\
\text { (1.47 to } 37.67)\end{array}$ \\
\hline Serogroup C infection & $16(62)$ & $32(24)$ & $\begin{array}{c}5.00 \\
(1.91 \text { to } 13.22)\end{array}$ & $\begin{array}{c}4.12 \\
\text { (1.53 to } 11.08)\end{array}$ \\
\hline $\begin{array}{l}\text { Onset to admission <25th } \\
\text { centile }\end{array}$ & $8(31)$ & $33(25)$ & $\begin{array}{c}1.33 \\
\text { (0.48 to } 3.64)\end{array}$ & $\begin{array}{c}1.29 \\
(0.42 \text { to } 3.89)\end{array}$ \\
\hline GP assessed illness as severe & $14(54)$ & $53(40)$ & $\begin{array}{c}1.74 \\
(0.78 \text { to } 3.20)\end{array}$ & $\begin{array}{c}1.83 \\
\text { (0.66 to } 5.12)\end{array}$ \\
\hline $\begin{array}{l}\text { Haemorrhagic rash before } \\
\text { admission }\end{array}$ & $22(85)$ & $103(78)$ & $\begin{array}{c}1.55 \\
(0.45 \text { to } 5.79)\end{array}$ & $\begin{array}{c}0.66 \\
\text { (0.14 to } 3.09)\end{array}$ \\
\hline $\begin{array}{l}\text { Septicaemic disease without } \\
\text { localisation }\end{array}$ & $21(81)$ & 77 (58) & $\begin{array}{c}3.00 \\
(0.99 \text { to } 9.72)\end{array}$ & $\begin{array}{c}2.68 \\
(0.73 \text { to } 9.86)\end{array}$ \\
\hline $\begin{array}{l}\text { Oral antibiotics in week before } \\
\text { admission }\end{array}$ & $2(8)$ & $8(6)$ & 1.29 (0 to 7.24$)$ & $\begin{array}{c}2.16 \\
(0.30 \text { to } 15.55)\end{array}$ \\
\hline
\end{tabular}

*Adjustments for other factors shown in table with logistic regression.

$\ddagger$ Six cases excluded because we could not determine whether or not penicillin had been administered before admission.

only two groups classified by severity and vital signs were seldom recorded by the general practitioner. So one likely explanation for the high odds ratio we obtained for mortality is that there is a strong residual selection bias towards giving penicillin to the most severely ill children. This is supported by the finding that children who received penicillin had more severe disease as measured by GMSPS on admission.

An alternative explanation for the increased severity of disease in the children treated with penicillin is that penicillin precipitates shock by liberating endotoxin during bacteriolysis before the child reaches hospital..$^{5-8}$ Though the previous studies by Brandtzaeg et al did not shown a rise in plasma endotoxin concentrations after administration of either penicillin or chloramphenicol, ${ }^{9}$ we explored this alternative explanation by looking at the relation between severity on admission and transit time. We reasoned that if penicillin increased severity by liberating endotoxin during bacteriolysis, the severity of disease on admission would increase with the time taken for the child to arrive at hospital. We found no evidence of this. There was no change in the severity of the disease on hospital presentation with increasing time up to three hours after administration of penicillin. Furthermore, severity was not increased in children who did not receive penicillin in periods up to three hours taken

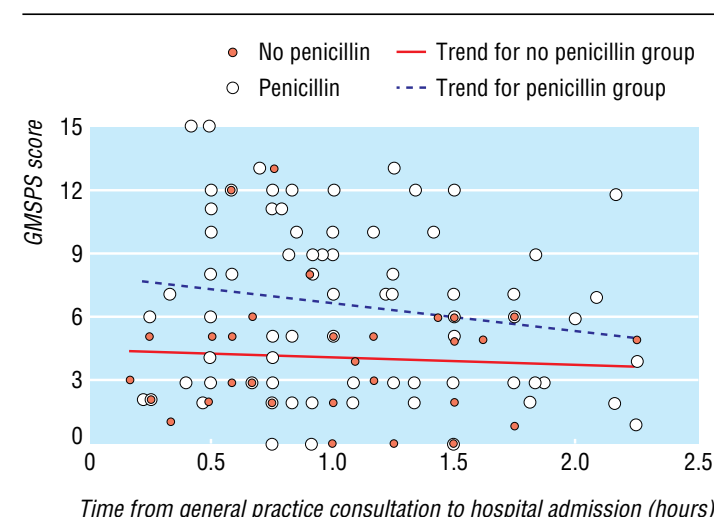

Fig 2 Severity of illness on admission to hospital (GMSPS score) according to time from general practice consultation and whether or not penicillin had already been administered 
to reach hospital. This suggests that a short delay without penicillin is not deleterious.

Why did the original paper by Cartwright et $\mathrm{al}^{1}$ (and a contemporaneous paper by Strang and $\mathrm{Pugh}^{10}$ ) suggest a positive benefit from penicillin when we and our Danish colleagues show such a clear association with poor outcomes? One contributory explanation for the difference lies in the inclusion or exclusion of children in whom the general practitioner did not make the diagnosis of meningococcal disease and who were therefore unlikely to receive penicillin before admission. If we had included the 166 children who were seen but not diagnosed by general practitioners and who reached hospital at a median of 12 hours later without having parenteral penicillin before admission, the estimated crude odds of death after penicillin would be reduced from 5.96 to 1.45 , at the upper limit of the $95 \%$ confidence interval of the estimate by Cartwright et al. ${ }^{1}$ The current discrepancies can be answered only by a randomised controlled trial.

(Accepted 23 February 2006)

doi $10.1136 /$ bmj. 38789.723611 .55

\section{Research}

\section{Amendment}

This is version 2 of this article. It incorporates various proofreading changes, none of which alters the findings of the study.

Robert Booy contributed substantially to the design of the original study. Clare Phillips assisted with the data collection.

Contributors: ML designed and oversaw the original study. NN recruited the parents, collected the data and interviewed parents and general practitioners. $\mathrm{DM}, \mathrm{AH}$, and RMW obtained funding for the Oxford research team. AH wrote the primary care protocol for this study. RP and MT performed the data analysis. AH and RMW supervised the data analysis. AH and DM wrote the manuscript. RMW, ML, MT, RP, and NN all made contributions to the redrafting. AH is guarantor for the paper.

Funding: The data were collected in conjunction with the research division of the Royal College of Paediatrics and Child Health. The project was funded by the Meningitis Research Foundation who received a grant from the National Lottery Charities Board (now the Big Lottery Fund), which enabled support for part of this study. The research team in Oxford is supported by the UK Medical Research Council.

Competing interests: None declared

Ethical approval: South Thames multi-research ethics committee and all local research ethics committees in England, Wales, and Northern Ireland.

1 Cartwright K, Reilly S, White D, Stuart J. Early treatment with parenteral penicillin in meningococcal disease. BMJ 1992;305:143-7.

2 Sorensen HT, Nielsen GL, Schonheyder HC, Steffensen FH, Hansen I, Sabroe S, et al. Outcome of pre-hospital antibiotic treatment of meningococcal disease. J Clin Epidemiol 1998;51:717-21.

3 Norgard B, Sorensen HT, Jensen ES, Faber T, Schonheyder HC, Nielsen GL. Pre-hospital parenteral antibiotic treatment of meningococcal disease and case fatality: a Danish population-based cohort study. J Infect 2002;45:144-51.

4 Ninis N, Philips C, Bailey L, Pollock JI, Nadel S, Britto J, et al. The role of healthcare delivery in the outcome of meningococcal disease in children: case control study of fatal cases and survivors. BMJ 2005;330:1475-8.

5 Mellado M, Rodriguez-Contreras R, Mariscal A, Luna J, Delagado-Rodriguez M, Galvez-Varges R. Effect of penicillin and chloramphenicol on the growth and endotoxin release by N meningitidis. Epidemiol Infect 1991;106:283-8.

6 meningitidis. Epidemiol Infect 1991;106:283-8.

7 Brandtzaeg P, Kierulf P, Gaustad P, Skulberg A, Bruun JM, Halvorsen S, et al. Plasma endotoxin as a predictor of multiple organ failure and death in systemic meningococcal disease.J Infect Dis 1989;159:195-204.

8 Andersen B, Solberg O. The endotoxin-liberating effect of antibiotics on meningococci in vitro. Acta Pathol Microbiol Scan 1980;88:231-6.

\section{What is already known on this topic}

Current guidance to UK general practitioners is to give penicillin to children with suspected meningococcal infection before they are admitted to hospital

\section{What this study adds}

Children who receive penicillin before admission have more severe disease on reaching hospital

Children given penicillin may have had more severe disease when they were first seen by a general practitioner

An adverse effect of penicillin in the first hour cannot be excluded, though this cannot be explained by our current understanding of biological mechanisms 


\section{Research}

9 Brandtzaeg P, Kierulf P, Gaustad P, Dobloug J, MollnesTE, Sirnes K. Systemic meningococcal disease: a model infection to study acute endotoxinemia in man. Prog Clin Biol Res 1988;272:263-71.

10 Strang J, Pugh E. Meningococcal infections: reducing the case-fatality rate by giving penicillin before admission to hospital. BMJ 1992;305:141-3.

(Accepted 23 February 2006)

Department of Primary Health Care, Institute of Health Sciences, University of Oxford, Oxford OX3 7LF

Anthony Harnden university lecturer in general practice

Matthew Thompson clinical lecturer in general practice

Rafael Perera senior research fellow in statistics

Richard Mayon-White epidemiologist

David Mant professor of general practice

Department of Paediatrics, Faculty of Medicine, Imperial College, London

Nelly Ninis research fellow in paediatrics

Division of Medicine, Brighton and Sussex Medical School, Brighton

Michael Levin professor of experimental medicine

Correspondence to: A Harnden anthony.harnden@dphpc.ox.ac.uk 